DOI: https://doi.org/10.24297/jbt.v8i0.8128

\title{
Therapeutic effectiveness of Hydroxyapatite Nanoparticles and Pulsed Electromagnetic Field in Osteoporosis and Cancer
}

\author{
Divya Prakash ${ }^{1 *}$, Shikha S Chauhan ${ }^{1}$, Jitendra Behari² \\ ${ }^{1}$ Department of Biochemistry and Molecular Biology, Pennsylvania State University, University Park, USA \\ ${ }^{2}$ Amity Institute for Environmental Toxicology, Amity University, Uttar Pradesh, India \\ dxp31@psu.edu
}

\begin{abstract}
The emergence of nanotechnology has had a profound effect on many areas of healthcare and scientific research. Several studies reported the importance Hydroxyapetite Nanoparticles in the biomedical field in general, and in emerging areas such as implants, drug delivery, cancer, composites, coatings, and ceramic materials in particular. On the other hand, low level Pulsed electromagnetic field (PEMF) therapy presents several potential advantages including non-invasiveness, safety, highly influential in the fracture repair process, lack of toxicity for non-cancerous cells, and the possibility of being combined with other available therapies. It has also been observed that the combined effect of these two can accelerate the osteognic and anticancer activity in the osteoporotic and carcinoma cell lines respectively. The objective of this review is to provide a broad recount of the applications of PEMFs and Hydroxyapatite nanoparticles in osteoporosis and cancer and to then demonstrate what is further required for enhanced therapeutic outcomes.
\end{abstract}

Keywords: Osteoporosis, Cancer, Hydroxyapatite Nanoparticles, Pulsed Electromagnetic Field

\section{Hydroxyapatite Nanoparticles (HApN):}

In spite of the several developments in drug therapy and disease management, the research of pioneering methods to targets disease remains a very dynamic research field because of the array of unsettled therapeutic problems. Scientists are working now to create novel nanostructures that serve as new kinds of drugs for treating cancer, osteoporosis and Parkinson's. Presently [1-3], nanosized materials such as polymeric nanoparticles, gold nanoparticles, quantum dots, and liposomes are broadly used in the design of drugs, optical devices, imaging agent, gene-delivery systems, catalysts and biosensors. Over recent decade, because of biocompatibility, bioceramic based nanoparticles has enticed substantial attraction [4]. Out of several types of bioceramics, hydroxyapatite ( $\mathrm{HAp})$ is extremely important owing to its structural and chemical similarities to bone phosphates hydroxyapatite. Due to its bioactive and biocompatible properties, HAp has been found broad applications in the biomedical. HAp has been frequently used in bone tissue regeneration, enhancing osteogenesis and as an implanting material and coating material as well [5]. To enhance the bioactivity of implanting material, HAp is generally coated on the surface of the implanting materials. Furthermore, HAp is also a suitable material for carrying drugs to the targeted sites, or for a slow and unremitting release of drugs, which will eventually help in stimulating the growth of osteoblastic cells [5-7]. Moreover, HAp has shown to be used for numerous applications in the fields of protein chromatography, fertilizers, pharmaceuticals, water treatment, biomedicine owing to its stability with wide range of $\mathrm{pH}(4-14)[5,8,9]$.

Hydroxyapatite nanoparticles $\left[\mathrm{HApN} ; \mathrm{Ca}_{10}\left(\mathrm{PO}_{4}\right)_{6}(\mathrm{OH})_{2}\right]$ is a member of the apatite family that usually consists of $\mathrm{Ca}$ and phosphates. Due to its chemical composition and definite orientation [10, 11], HAp crystal comprised two binding sites, i.e. "Ca" sites (positive charged) and " $\mathrm{PO}_{4}$ " sites (negative charged) (figure.1). These two binding sites interact with theirs opposite charge protein/residues [12, 13]. 


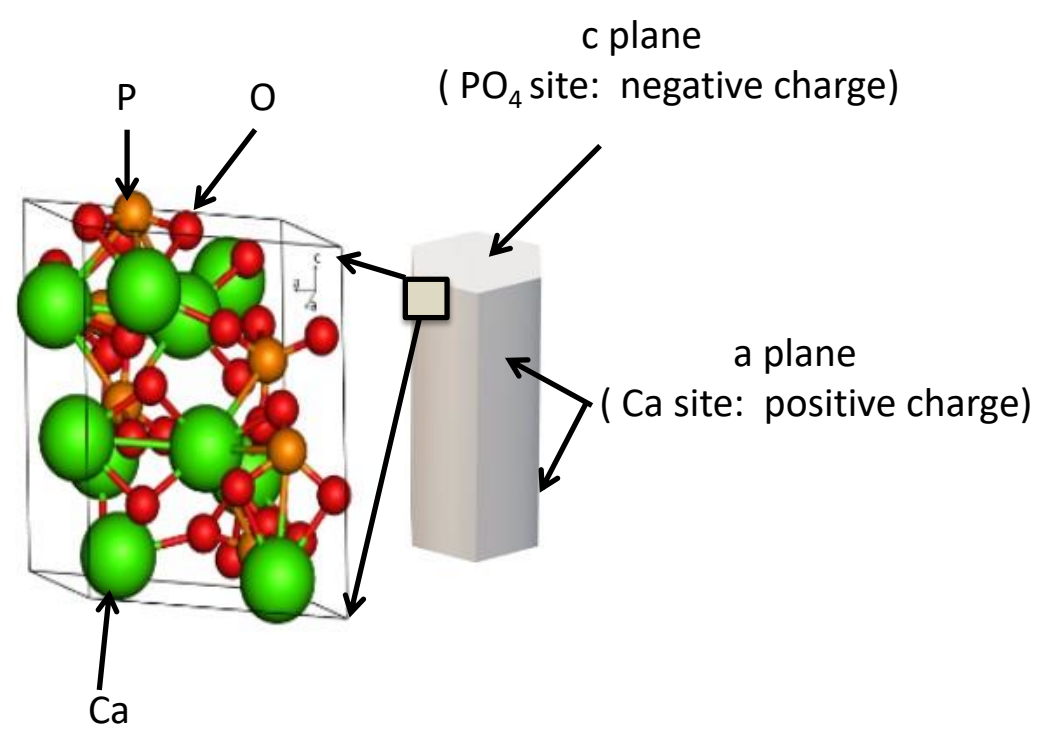

Figure 1: Hexagonal crystal structure of hydroxyapatite with "c" and "a" plane comprising $\mathrm{Ca}$ and $\mathrm{PO}_{4}$ sites respectively. Molview 2.2 version software was used to draw the crystal structure of HAp.

\section{Role of Hydroxyapetite Nanoparticles (HApN) in Osteoporosis:}

Hydroxyapatite $\left[\mathrm{HApN} ; \mathrm{Ca}_{10}(\mathrm{PO} 4)_{6}-(\mathrm{OH})_{2}\right]$ nanoparticles are chemically similar to the mineral component of bones and hard tissues in mammals. It is one of the few materials that are classified as bioactive, which means that it will support bone growth and osteointegration when used in orthopedics. Crystalline HAp particles are the typical mineral used in repair and may promote osteoblast cell adhesion [14, 15]. These particles are plateshaped and hundreds of nanometers long $[16,17]$. It is suggested that the basic inorganic building blocks of bone may be these nanosized apatite particles [18]. Tens to hundreds of these nanoblocks, in the collagen matrix, combine into self-assembled biomaterials that have remarkable physical and chemical features [19] such as unique mechanical strength, insensitivity to growth/dissolution, and flexible structure [20] .Thus, features of HAp nanoparticles may more closely approximate features of HAp during biomineralization. Therefore, HAp nanoparticles may promote the adhesion, proliferation and synthesis of alkaline phosphatase (ALP) in osteoblasts and lead to more rapid repair of hard tissue injury [21, 22].

It has been reported that HApN can be a better candidate in biomedical applications [23, 24]. However, the size dependent effects of these nanoparticles are not understood. Although conventional calcium phosphate materials have been well studied and shown to be biocompatible, the utility of smaller HAp particles as biomedical materials has received attention but the synthesis of HAp nanoparticles of well-defined size has been difficult to control $[25,26]$. Therefore, new fabrication method should be used to engineer nanoparticles which can be useful for difference purposes [3]. Thus, questions concerning the mechanisms whereby cells detect and respond to HAp nanoparticles remain unresolved [27]. It is likely that HApN involve modulation of the interfacial forces that guide the organization of cytoskeletal elements and membrane receptor in cells. This, in turn, may modify intracellular signaling, binding sites of proteins and integrin signaling [28]. This hypothesis suggests that it may be possible to optimize the functionality of cells on the basis of size and other features of HAp nanoparticles. Information gained by investigations based on this hypothesis may also contribute to a more general understanding of biomineralization and biomaterials. The cell culture experiments on bone marrow mesenchymal stem cells (MSCs) showed improved cytophilicity of the nanophase mineral as compared with conventional HAp. Greater cell viability and proliferation of MSCs were measured on the nano HAp, remarkably for $20 \mathrm{~nm}$ sized particles [29].

In our earlier studies [30, 31], we have reported the effect of Silicon substituted hydroxyapetite nanoparticles (Si-HApN) on hind-limb suspended (HLS) wistar rat. A significant increase in BMD, Calcium (Ca), Phosphorous 
(P), type I collagen, and ALP activity in femur and tibia in hind-limb bone of Si-HApN ( $20 \mathrm{mg} / 250 \mathrm{~g}$ body weight) treated wistar rat ( HLS+HAP) as compared to control (HLS) .Our finding indicates that HApN has potential to encounter the bone loss.

An important but unsolved question is how the cells can recognize the particle size of HAp nanoparticles. It is well known that cells are inherently sensitive to their surroundings. It is suggested that the dissolution of HAp nanoparticles (small size and poor crystallinity) will increase concentrations of calcium and phosphate in the medium and thereby may alter the gene expression, alkali phosphate and proteins [32]. However, other funding contradict the dissolution of HAp in solution [29].We observed significant increase in ALP activity, type I collagen and osteocalcin concentration in HLS + HAp group rats. It indicates that $20 \mathrm{mg} / 250 \mathrm{gm}$ body weight of Si-HAp can induce and enhance the expression level of bone formation marker genes. Furthermore, the zeta potential measurements can provide the interfacial properties of the nanoparticles. HApN particles have a slightly negative zeta potential in water at pH 7.4 [33]. Since the electronic potential of cell membranes is known to be always negative; the positive or weakly negative particles are suitable for adsorption by cells. Another possible explanation is that the quantity of proteins adsorbed on particles positively correlates with their specific surface area $[33,34]$. Nanosized particles adsorbed significantly greater amounts of proteins due to the presence of both positive (" $\mathrm{Ca}$ ") and negative (" $\mathrm{PO}_{4}$ ") sites and induce enhancement of subsequent cell adhesion and proliferation in hind-limb suspended wistar rat treated with HApN (HLS + HApN) and in hind-limb suspended wistar rat treated with both HApN and low level pulsed electromagnetic field (HLS + HApN + PEMF) group rats. It is suggested that PEMF helps to accelerate the process [30, 31].

\section{Role of Hydroxyapetite Nanoparticles (HApN) in Cancer:}

Exploring new materials for treatment and investigating the mechanism are important. With the development of nanometer technology, hydroxyapatite nanoparticle, a novel inorganic material, was found to be able to inhibit tumor cell proliferation. Hydroxyapatite $\left[\mathrm{HAp} ; \mathrm{Ca}_{10}(\mathrm{PO} 4)_{6}-(\mathrm{OH})_{2}\right]$ one of major inorganic components of mammalian bones, has been used extensively and successfully as bone defect filling material, as well as medicine bearer and coating material [35-37]. In recent years $[2,4,5,15,38,39]$, nanoscale hydroxyapatite (HApN), a novel biomedical material, which diameter less than $100 \mathrm{~nm}$, has been reported that not only has better biocompatibility than HAP but also anti-cancer activity. It has been shown $[40,41]$ to inhibit the proliferation of various tumors, such as hepatoma, colon cancer, and osteosarcoma. Moreover, the antiproliferation effect of nano-HAp has been shown to be due to induction of apoptosis. However, the actual molecular mechanism of $\mathrm{HApN}$-induced apoptosis remains unclear.

Several studies [42-45] on the effects of HApN on human gastric cancer SGC-7901 cells showed that HApN significantly reduced cell viability and induced apoptosis in SGC-7901 cells characterized by hypodiploid DNA contents, morphological changes and DNA fragmentation. The increase in apoptosis was accompanied with the increased expression of $\mathrm{Bax}$, a pro-apoptotic protein and decreased expression of $\mathrm{BCl}-2$, an antiapoptotic protein, the decrease of mitochondrial membrane potential and the release of cytochrome $c$ from mitochondria into cytosol. Furthermore, while HApN induced the activation of caspases-3 and 9, no activation of caspases-8 was observed.

Moreover, the exact internalization pathway into the cells represents the first necessary step towards the detailed investigation and optimization of the functional mechanism of HAp nanoparticles. In contrast to the organic and spheric latex particles, HAP nanoparticles are inorganic and needle shaped. Recent studies intensively documented the internalization of HAP nanoparticles into hepatoma cells via transmission electron microscopy and thus suggested phagocytosis as possible entrance pathway [46]. Since, the particle size can influence the pathway of internalization $[47,48]$, the increase of the particle size due to the nanoparticle agglomeration in the presence of organic medium has to be taken into account for the discussion of the internalization mechanism. The uptake of latex microspheres with a diameter smaller than $200 \mathrm{~nm}$ involved clathrin-coated pits while caveolae-mediated internalization became the predominant pathway of entry for particles of $500 \mathrm{~nm}$ in size [46]: 


\section{Pulsed electromagnetic fields (PEMF):}

In PEMF, a time-varying electrical current is passed through a conductor to produce a magnetic field based. Exposure to PEMFs in the $0-300 \mathrm{~Hz}$ range is a therapeutic tool widely used for the treatment of several diseases including osteoarthritis, postsurgical pain and edema, Parkinson's disease and easing of vasodilatation and angiogenesis producing direct stimulation to excitable cells [49-51]. Initially it was it was thought that PEMFs induced forces through piezoelectricity [52-54]. Further, it has been reported by Funk et.al that electric fields exemplify forces at the surface of molecules, cell membranes and even the whole body, while magnetic fields penetrate deeper going inside the cell influencing chemical and biochemical reactions[55].

\section{Role of low level Pulsed electromagnetic fields in Osteoporosis:}

Pulsed electromagnetic fields (PEMF) have been successfully used for several decades to treat a wide range of bone disorders such as delayed and nonunion fractures, fresh fracture healing, prevention and reversal of osteoporosis[53]. The therapeutic effects of PEMF were first demonstrated in bone by Basset and colleagues[52], whose reports led to clinical trials and widespread commercial availability. Subsequently, PEMF has been demonstrated in blinded trials to be a safe and effective means of treating nonhealing bone fractures[56, 57].

Our device, known as an electrical bone stimulator, has been used to treat fractures and control osteoporosis. It emits a PEMF, which is applied to the chosen site of the long bone. The bone stimulator (Table 1, Figure 2) is connected to a pair of capacitor electrodes, which are applied over the skin.

Table 1 specification of Bone Stimulator:

\begin{tabular}{|l|l|}
\hline Carrier Frequency: & $14.0 \mathrm{MHz}$ \\
\hline Modulated Frequency: & $16.0 \mathrm{~Hz}$ \\
\hline Amplitude: & $10 \mathrm{~V}$ (peak to peak) \\
\hline Output Wave Shape: & Square \\
\hline $\begin{array}{l}\text { Electrode diameter: } \\
\text { Average electric field between } \\
\text { electrodes: }\end{array}$ & 7.8 Volt / m \\
\hline
\end{tabular}




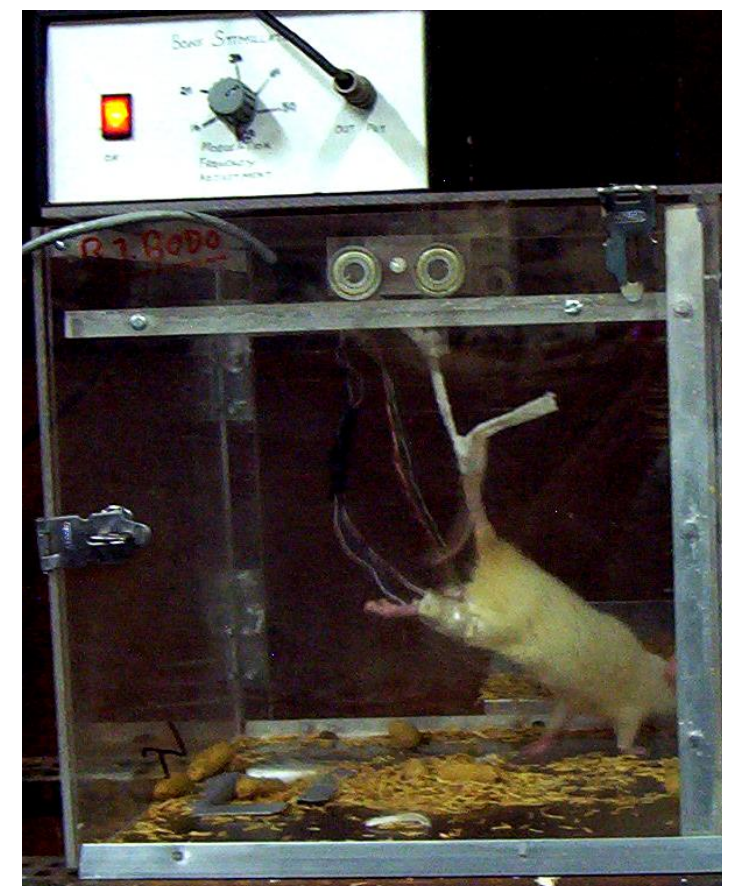

Figure 2: Pulsed electromagnetic field treatment on hind limb suspended wistar rat by Bone Stimulator.

Bone stimulator emits low level electromagnetic energy. In our earlier studies, we have demonstrated that capacitive coupling of pulsed electromagnetic fields (CC-PEMF) exposure promote the restoration of the bone loss in tail-suspension induced[30], ovariectomy-induced [58, 59] and nurectomized osteoporosis [60] .Other studies also shown that PEMF is capable of preventing bone loss in animal models of disuse osteoporosis [5254, 61, 62], tail-suspension-osteoporosis [63] and ovariectomy-induced osteoporosis [64-68]. Clinical investigations further confirmed that PEMF could help enhance bone mineral density and inhibit bone loss in human patients [69-71]. Despite this knowledge, we have to realize that the stimulus efficacy of PEMF was influenced by many factors, such as PEMF parameters [72], the duration of PEMF exposure [73] and the placement of PEMF generator [74] and others. However, due to the complexity of PEMF biological effects, there are still several other factors which have not yet been investigated.

Although, Pulsed electromagnetic fields (PEMF) are being used clinically to promote bone healing but relatively little is known about the mechanisms involved. EMF possibly directly alters ion binding and/or transport that leads to trigger the cascade of biological processes related to tissue growth and repair [75, 76]. In electromagnetic field, magnetic fields (MFs) penetrate deeper going inside the cell influencing chemical and biochemical reactions whereas electric fields (EFs) represent forces at the surface of molecules, cell membranes and even the whole body $[75,77,78]$. To date, despite having a somewhat concrete understanding, there is no conclusively defined mechanism of action. The main reason for such ambiguity as to how PEMFs act is the highly complex nature of the fracture healing process itself. Bone repair at molecular level comprised a number of signaling molecules like pro-inflammatory cytokines (e.g. interleukin-1 and interleukin-6), transforming growth factor-beta (TGF-b) super family and other growth factors (e.g., bone morphogenic protein 2, insulin- like growth factor and growth differentiation factor) and angiogenic factors such as angiopoietin and vascular endothelial growth factors [79-81]. These factors work to induce differentiation and proliferation of mesenchymal stem cells (MSCs) into cartilage, fibrous tissue and bone.

It has shown that PEMF causes osteoblasts to produce paracrine factors, including transforming growth factor beta-1 (TGF-b1), prostaglandin E2 (PGE2) and bone morphogenetic protein-2 (BMP-2) [82-84]. The PEMF also induces human mesenchymal stem cells (MSCs) to produce TGF-b1 and PGE2, but only when they are cultured on calcium phosphate substrates in osteogenic medium and this is enhanced when the cells are treated with BMP-2 to induce osteoblastic differentiation[85]. These studies indicate that PEMF affects cells in the osteoblast 
lineage to produce factors that stimulate osteoblast differentiation. The observation that TGF-b1 also inhibits osteoclast activity suggests that PEMF may stimulate production of other factors that modulate bone resorption[86]. In addition to this, PEMF induces cells in the osteoblast lineage to produce osteoprotegerin (OPG).

The effect of PEMF was evident only when the cells were cultured on CaP disks, supporting the hypothesis that responses of osteoblastic cell to local and systemic factors, including mechanical and biophysical stimuli, are substrate dependent $[86,87]$. Integrin expression is sensitive to surface properties, and there is a shift in integrin signaling when osteoblast-like cells are cultured on tissue culture polystyrene (TCPS) or calcium phosphate. The effects of PEMF on the OPG/RANKL (osteoprotegerin/receptor activator of nuclear factor kappa-B ligand) system were specific to OPG. No changes in RANKL mRNA or soluble RANKL protein were detected, regardless of the cell model examined. This suggests that PEMF acts via a signaling pathway that is distinct from pathways that mediate RANKL expression or secretion. Thus PEMF acts differently on cells in the osteoblast lineage depending on their state of differentiation [88]. As noted previously the stimulatory effects of PEMF on MSCs were greater in a culture environment that promoted osteoblast differentiation: growth on a CaP substrate in osteogenic media. In younger cultures, treatment of MSCs with BMP-2 to induce osteoblast differentiation also enhanced response to PEMF [86]. In more mature cultures, when more of the cells were expressing an osteoblast phenotype, no further enhancement of response was noted in BMP-2 treated cultures over that seen with PEMF alone [88]. However, BMP-2 stimulated cells were further stimulated by PEMF. BMP-2 has also been shown to increase OPG [89], suggesting that BMP and PEMF acted via different pathways.

In vitro PEMF studies focused on osteoblasts and its precursor, whereas the in vivo fracture environment is a complex interconnected system of different cell types. There exists a particularly intimate connection, both physical and biochemical, between blood vessels and bone cells in the multiple steps required for bone healing. Since all cells are exposed to PEMF during therapy, so, to is important to examine the effect of PEMF on both the paracrine and autocrine cell interaction between osteoblasts and endothelial cells in vitro. Osteoblasts and endothelial cells are in close approximation within the basic multicellular unit (BMU) of bone healing. In an attempt to understand the in vivo mechanism of effect of PEMF, it is therefore important to examine its effect on osteoblast-endothelial communication. Studies have demonstrated a reciprocal functional and regulatory relationship between osteoblasts and endothelial cells during osteogenesis that involves the pro-angiogenic vascular endothelial growth factor (VEGF) family, and in particular VEGF-A [90-92]. The clinical effect of PEMF on endothelial cells during bone healing may not be limited to a direct autocrine effect. Neighboring osteoblasts within the electrical field can affect endothelial cell proliferation in a paracrine manner through release of a soluble factor. It was found that PEMF acts by promoting angiogenesis through the coordinated release of FGF2 and to a lesser extent several other vascular growth factors (Ang-2, TPO and EGF) [93]. This suggests that PEMF may facilitate healing by augmenting the interaction between osteogenesis and blood vessel growth.

The vast majority of bone marrow mesenchymal stem cells (BMMSCs) are present in the quiescent state (G0) while a small number of cells are actively engaged in proliferation (approximately $10 \%$ at $\mathrm{S}+\mathrm{G} 2+\mathrm{M}$ ). However, flow cytometric analysis revealed that PEMF treatment of chondrocytes led to significantly increased cell numbers in the $\mathrm{S}+\mathrm{G} 2+\mathrm{M}$ cell cycle phase $[94,95]$. The change of cell cycle progression of BMMSCs under PEMF treatment might be attributed to the alteration of cell membrane potential resulting from PEMF exposure. Previously [78], it is suggested that the possible mechanism of electromagnetic fields on cells is the forcedvibration of all the free ions on the surface of a cell's plasma membrane. Moreover, it was observed that voltagegated delayed rectifier $\mathrm{K}^{+}$current and $\mathrm{Ca}^{2+-}$ activated $\mathrm{K}^{+}$current channels were changed during progress from $\mathrm{G} 1$ to $\mathrm{S}$ phase, and functional expression of ion channels could regulate proliferation in undifferentiated rat mesenchymal stem cells [96]. These findings led us to infer that PEMF exposure changed the expression of ion channels and induced membrane hyperpolarization of BMMSCs and therefore resulted in the alteration of the cell cycle progression.

\section{Role of low level Pulsed electromagnetic fields in Oncology:}


The resistance of tumor cells to antineoplastic agents is a major obstacle during cancer chemotherapy. In fact, many patients do not respond to treatments and die due to metastasis, the main mechanism being drug resistance, the so-called multidrug resistance (MDR) phenomenon. The reason for this resistance is the expression of a membrane glycoprotein, named P-glycoprotein or P-170, that acts as a drug extracting pump, reducing the intracellular level of the antitumor agent $[97,98]$. On exposure of PEF (typical parameters: $1 \mathrm{kV} / \mathrm{cm}$, $100 \mu \mathrm{s})$, lipid bilayer in cell membrane could temporarily rearrange, leading to the formation of aqueous channels that are often called pores [99-101]. Such changes will make cell membrane more permeable to a variety of hydrophilic molecules, while there is no effect on the intramembranous organelles (e.g. nucleolus). After pulsing, in most cases, these pores will reseal without any damage to cell. This physical procedure of transient pores appearing at cell membrane is termed electroporation. The electroporation therapy, combining PEF with chemotherapy, has been applied for treating tumor [102-104], such as head-neck cancer, skin cancer, pancreatic cancer and liver cancer. In this way, exogenous molecules like HApN, cytostatics can penetrate more efficiently by exposure of the cells to a magnetic or electric field, which increases the cell membrane permeability. The higher uptake of drugs enhances cell killing[103]. On the other hand [105], it has been reported that pulsed magnetic fields (5.25 mT peak, 250 pulses/sec) enhance the potency of daunorubicin against KB-ChR-8-5-11 cells. It was suggest that the mechanism involved may be the inhibition of the efflux pump, P-glycoprotein. In addition, it was observed that $1.2 \mathrm{mT}, 60 \mathrm{~Hz}$ magnetic fields partially block tamoxifen's inhibitory action on growth of human mammary tumor (MCF-7) cells in vitro [106]. Animal studies have shown that the use of magnetic fields can enhance drug delivery across biological barriers (rat abdominal skin), using benzoic acid as the drug candidate [107].

In vitro study of PEMF on various human cancer cell lines like breast cancer (e.g., MCF7, MDA-MB- 231 and T47D), pheochromocytoma-derived (PC12), and colon cancer (SW-480 and HCT-116) showed blockage of the development of neovascularization required for tumor supply, ant-proliferative and mitotic spindle disruption and induced genetic instability by reducing the stringency of the late-cycle (G2) checkpoint [108-111]. Moreover, study shows that PEMF treatment is target specific [112]. It has been reported that PEMF therapy (parameters: frequency of $20 \mathrm{~Hz}$, intensity of $3 \mathrm{mT}$ ) with exposure time of $60 \mathrm{~min} /$ day for up to 3 days induce apoptosis in human breast adenocarcinoma cells (MCF7), but not to normal breast epithelial cells (MCF10). Though target specific behavior of PEMF is promising, but exposure was limited to 3 days only. Hence, long-term PEMF exposure needs to be evaluated in further studies considering the fact that effectiveness of PEMF is severely linked to the signal parameters, exposure magnitude, duration, signal shape, duration of treatment as well as the type of cells exposed to the magnetic field $[113,114]$.

In vivo study of PEMF on various mice or rat model like T-cell immnuodeficient female nude mice, wistar rat and $23 \mathrm{SKH}-1$ immunocompetent albino mice showed tumor reduction, a significant decrease in serum AFP (a serum glycoprotein elevated in cancer patient and used as a carcinoma marker) level, significant pyknosis, shrinkage of tumor cell nuclei [115-117]. However, effectiveness of PEMF therapy reported to be proportional to the exposure period. In case of mouse models of breast cancer, mice exposed for 6 hrs for four weeks showed a significant reduction in tumor size, possibly due to the inhibition of angiogenesis that may suppress the formation of blood vessels in tumor tissues, reducing the tumor growth [118]. Moreover, to the certain extends PEMF treatment reported to be effective to treat patient suffering from advanced HCC, glioblastoma multiforme, colorectal, ovarian, pancreatic, prostrate and thyroid cancer $[119,120]$.

\section{Future trends in osteoporosis and cancer research with PEMF and HApN:}

Combination of Nanoparticles and Pulsed Electromagnetic Field could be used as a positive countermeasure for osteoporosis and cancer disease. Earlier, we reported that a combination of low level PEMF and HAp nanoparticles has potential to control bone loss induced by simulated microgravity [30, 31].

It can be suggested that the future prospects to treat diseases lies somewhere in the combination therapy. It should be noted that combination may lead to development toxicities, which need to be evaluated along with its potential to control the disease. Research in next decade with PEMF and Nanoparticles will definitely add 
information in area of medicine. Clinical studies have used PEMF therapy for both osteoporosis and cancer treatment. These studies show that PEMF therapy is safe and promising compared to other available cancer and osteoporosis therapies. On the other hand, due to its bioactive and biocompatible properties, HAp has been shown to be used as a countermeasure to prevent both osteoporosis and cancer. In the future, PEMFs with $\mathrm{HApN}$ could be used synergistically in the field of osteoporosis and oncology.

\section{References:}

1. De Jong WH, Borm PJ: Drug delivery and nanoparticles: applications and hazards. International journal of nanomedicine 2008, 3(2):133.

2. Maia ALC, Cavalcante $\mathrm{CH}$, de Souza MG, Ferreira CdA, Rubello D, Chondrogiannis S, Cardoso VN, Ramaldes GA, de Barros AL, Soares DC: Hydroxyapatite nanoparticles: preparation, characterization, and evaluation of their potential use in bone targeting: an animal study. Nuclear medicine communications 2016, 37(7):775-782.

3. Singh DK, Krotkov RV, Xiang $\mathrm{H}, \mathrm{Xu} \mathrm{T}$, Russell TP, Tuominen MT: Arrays of ultrasmall metal rings. Nanotechnology 2008, 19(24):245305.

4. Jafari S, Adibkia K: Application of hydroxyapatite nanoparticle in the drug delivery systems. J Mol Pharm Org Process Res 2015, 3:1-2.

5. Haider A, Haider S, Han SS, Kang I-K: Recent advances in the synthesis, functionalization and biomedical applications of hydroxyapatite: a review. Rsc Advances 2017, 7(13):7442-7458.

6. Koutsopoulos S: Synthesis and characterization of hydroxyapatite crystals: a review study on the analytical methods. Journal of Biomedical Materials Research: An Official Journal of The Society for Biomaterials, The Japanese Society for Biomaterials, and The Australian Society for Biomaterials and the Korean Society for Biomaterials 2002, 62(4):600-612.

7. Haider A, Gupta KC, Kang I-K: PLGA/nHA hybrid nanofiber scaffold as a nanocargo carrier of insulin for accelerating bone tissue regeneration. Nanoscale research letters 2014, 9(1):314.

8. Cao $\mathrm{H}$, Zhang $\mathrm{L}$, Zheng $\mathrm{H}$, Wang Z: Hydroxyapatite nanocrystals for biomedical applications. The Journal of Physical Chemistry C 2010, 114(43):18352-18357.

9. Cummings L, Snyder MA, Brisack K: Protein chromatography on hydroxyapatite columns. In: Methods in enzymology. vol. 463: Elsevier; 2009: 387-404.

10. KAWASAKI T, TAKAHASHI S, IDEDA K: Hydroxyapatite high-performance liquid chromatography: column performance for proteins. European journal of biochemistry 1985, 152(2):361-371.

11. Zhang S: Hydroxyapatite coatings for biomedical applications: CRC press; 2013.

12. Chen $X$, Wang $Q$, Shen J, Pan $H$, Wu T: Adsorption of Leucine-Rich Amelogenin Protein on Hydroxyapatite (001) Surface through- CoO-Claws. The Journal of Physical Chemistry C 2007, 111(3):1284-1290.

13. Shaw WJ, Campbell AA, Paine ML, Snead ML: The C-terminus of the amelogenin, LRAP, is oriented next to the hydroxyapatite surface. Journal of Biological Chemistry 2004.

14. Balasundaram G, Fleet J, Weaver C, Friedman A, Weatherman R, Webster T: Nanomaterials for osteoporosis treatment. In: Bioengineering Conference, 2005 Proceedings of the IEEE 37st Annual Northeast: 2005. IEEE: 170-171.

15. Balasundaram $G$, Sato $M$, Webster TJ: Using hydroxyapatite nanoparticles and decreased crystallinity to promote osteoblast adhesion similar to functionalizing with RGD. Biomaterials 2006, 27(14):2798-2805 \%U https://linkinghub.elsevier.com/retrieve/pii/S0142961205011634. 
16. Weiner S, Wagner HD: THE MATERIAL BONE: Structure-Mechanical Function Relations. Annual $\begin{array}{lllll}\text { Review of } & \text { Materials } & \text { 28(1):271-298 } & \text { \%U }\end{array}$ http://www.annualreviews.org/doi/210.1146/annurev.matsci.1128.1141.1271.

17. Mann S: Biomineralization: principles and concepts in bioinorganic materials chemistry, vol. 5: Oxford University Press on Demand; 2001.

18. Tang R, Wang L, Orme CA, Bonstein T, Bush PJ, Nancollas GH: Dissolution at the Nanoscale: SelfPreservation of Biominerals. Angewandte Chemie International Edition 2004, 43(20):2697-2701 \%U http://doi.wiley.com/2610.1002/anie.200353652.

19. Alivisatos AP: BIOMINERALIZATION: Enhanced: Naturally Aligned Nanocrystals. Science 2000, 289(5480):736-737 \%U http://www.sciencemag.org/cgi/doi/710.1126/science.1289.5480.1736.

20. Boskey AL, DiCarlo E, Paschalis $E$, West $\mathrm{P}$, Mendelsohn R: Comparison of mineral quality and quantity in iliac crest biopsies from high- and low-turnover osteoporosis: an FT-IR microspectroscopic investigation. Osteoporosis International 2005, 16(12):2031-2038 \%U http://link.springer.com/2010.1007/s00198-00005-01992-00193.

21. Cerroni L, Filocamo R, Fabbri M, Piconi C, Caropreso S, Condò SG: Growth of osteoblast-like cells on porous hydroxyapatite ceramics: an in vitro study. Biomolecular Engineering 2002, 19(2-6):119-124 \%U http://linkinghub.elsevier.com/retrieve/pii/S1389034402000278.

22. Yuasa T, Miyamoto $Y$, Ishikawa K, Takechi M, Momota Y, Tatehara S, Nagayama M: Effects of apatite cements on proliferation and differentiation of human osteoblasts in vitro. Biomaterials 2004, 25(7-8):1159-1166 \%U http://linkinghub.elsevier.com/retrieve/pii/S0142961203006550.

23. Olton D, Li J, Wilson ME, Rogers T, Close J, Huang L, Kumta PN, Sfeir C: Nanostructured calcium phosphates (NanoCaPs) for non-viral gene delivery: Influence of the synthesis parameters on transfection efficiency. Biomaterials 2007, 28(6):1267-1279 \%U https://linkinghub.elsevier.com/retrieve/pii/S0142961206009276.

24. Kalita SJ, Bhardwaj A, Bhatt HA: Nanocrystalline calcium phosphate ceramics in biomedical engineering. Materials Science and Engineering: C 2007, 27(3):441-449 \%U https://linkinghub.elsevier.com/retrieve/pii/S0928493106001469.

25. Al-Qasas NS, Rohani S: Synthesis of Pure Hydroxyapatite and the Effect of Synthesis Conditions on its Yield, Crystallinity, Morphology and Mean Particle Size. Separation Science and Technology 2005, 40(15):3187-3224 \%U http://www.tandfonline.com/doi/abs/3110.1080/01496390500385400.

26. Xiao F, Ye J, Wang Y, Rao P: Deagglomeration of HA during the precipitation synthesis. Journal of Materials Science 2005, 40(20):5439-5442 \%U http://link.springer.com/5410.1007/s10853-1000511919-10856.

27. Curtis A: Tutorial on the Biology of Nanotopography. IEEE Transactions on Nanobioscience 2004, 3(4):293-295 \%U http://ieeexplore.ieee.org/document/1363988/.

28. Curtis ASG, Gadegaard N, Dalby MJ, Riehle MO, Wilkinson CDW, Aitchison G: Cells React to Nanoscale Order and Symmetry in Their Surroundings. IEEE Transactions on Nanobioscience 2004, 3(1):61-65 \%U http://ieeexplore.ieee.org/document/1273510/.

29. Cai Y, Liu Y, Yan W, Hu Q, Tao J, Zhang M, Shi Z, Tang R: Role of hydroxyapatite nanoparticle size in bone cell proliferation. Journal of Materials Chemistry 2007, 17(36):3780 \%U http://xlink.rsc.org/?DOI=b705129h.

30. Prakash D, Behari J: Synergistic role of Hydroxyapatite Nanoparticles and pulsed electromagnetic field therapy to prevent bone loss in rats following exposed to simulated microgravity. In: Recent Advances in Microwave Theory and Applications: 2008. IEEE: 572-573. 
31. Prakash D, Behari J: Synergistic role of hydroxyapatite nanoparticles and pulsed electromagnetic field therapy to prevent bone loss in rats following exposure to simulated microgravity. Int $J$ Nanomedicine 2009, 4:133-144.

32. Wassell DTH, Hall RC, Embery G: Adsorption of bovine serum albumin onto hydroxyapatite. Biomaterials 1995, 16(9):697-702 \%U http://linkinghub.elsevier.com/retrieve/pii/014296129599697K.

33. Rouahi M, Champion E, Gallet O, Jada A, Anselme K: Physico-chemical characteristics and protein adsorption potential of hydroxyapatite particles: influence on in vitro biocompatibility of ceramics after sintering. Colloids and surfaces B: Biointerfaces 2006, 47(1):10-19.

34. Pezzatini S, Solito R, Morbidelli L, Lamponi S, Boanini E, Bigi A, Ziche M: The effect of hydroxyapatite nanocrystals on microvascular endothelial cell viability and functions. Journal of Biomedical Materials Research Part A: An Official Journal of The Society for Biomaterials, The Japanese Society for Biomaterials, and The Australian Society for Biomaterials and the Korean Society for Biomaterials 2006, 76(3):656-663.

35. Wahl D, Czernuszka J: Collagen-hydroxyapatite composites for hard tissue repair. Eur Cell Mater 2006, 11:43-56.

36. Queiroz A, Santos J, Monteiro F: Development of a system to adsorb drugs onto calcium phosphate materials. Journal of Materials Science: Materials in Medicine 2005, 16(7):641-646.

37. Moroni A, Pegreffi F, Cadossi M, Hoang-Kim A, Lio V, Giannini S: Hydroxyapatite-coated external fixation pins. Expert review of medical devices 2005, 2(4):465-471.

38. Fu Q, Zhou N, Huang W, Wang D, Zhang L, Li H: Effects of nano HAP on biological and structural properties of glass bone cement. Journal of Biomedical Materials Research Part A: An Official Journal of The Society for Biomaterials, The Japanese Society for Biomaterials, and The Australian Society for Biomaterials and the Korean Society for Biomaterials 2005, 74(2):156-163.

39. Uskokovic V: Nanostructured platforms for the sustained and local delivery of antibiotics in the treatment of osteomyelitis. Critical Reviews ${ }^{\mathrm{TM}}$ in Therapeutic Drug Carrier Systems 2015, 32(1).

40. Liu Z-S, Tang S-L, Ai Z-L: Effects of hydroxyapatite nanoparticles on proliferation and apoptosis of human hepatoma BEL-7402 cells. World journal of gastroenterology 2003, 9(9):1968.

41. Liu Z, Tang S, Ai Z, Hu J: Growth inhibition of human hepatoma and colon carcinoma cell line treated with hydroxyapatite nanoparticles. Chin J Exp Surg 2006, 23:266.

42. Ho Pk, Hawkins CJ: Mammalian initiator apoptotic caspases. The FEBS journal 2005, 272(21):54365453.

43. Compton MM: A biochemical hallmark of apoptosis: internucleosomal degradation of the genome. Cancer and Metastasis Reviews 1992, 11(2):105-119.

44. Schafer ZT, Kornbluth S: The apoptosome: physiological, developmental, and pathological modes of regulation. Developmental cell 2006, 10(5):549-561.

45. Chen X, Deng C, Tang S, Zhang M: Mitochondria-dependent apoptosis induced by nanoscale hydroxyapatite in human gastric cancer SGC-7901 cells. Biological and Pharmaceutical Bulletin 2007, 30(1):128-132.

46. Bauer IW, Li S-P, Han Y-C, Yuan L, Yin M-Z: Internalization of hydroxyapatite nanoparticles in liver cancer cells. Journal of Materials Science: Materials in Medicine 2008, 19(3):1091-1095.

47. Zuhorn IS, Visser WH, Bakowsky U, Engberts JB, Hoekstra D: Interference of serum with lipoplex-cell interaction: modulation of intracellular processing. Biochimica et Biophysica Acta (BBA)Biomembranes 2002, 1560(1-2):25-36. 
48. Rejman J, Oberle V, Zuhorn IS, Hoekstra D: Size-dependent internalization of particles via the pathways of clathrin-and caveolae-mediated endocytosis. Biochemical Journal 2004, 377(1):159169.

49. Iannitti $T$, Fistetto $G$, Esposito A, Rottigni $V$, Palmieri B: Pulsed electromagnetic field therapy for management of osteoarthritis-related pain, stiffness and physical function: clinical experience in the elderly. Clinical interventions in aging 2013, 8:1289.

50. Vadalà M, Vallelunga A, Palmieri L, Palmieri B, Morales-Medina JC, lannitti T: Mechanisms and therapeutic applications of electromagnetic therapy in Parkinson's disease. Behavioral and Brain Functions 2015, 11(1):26.

51. Strauch $B$, Herman $C$, Dabb R, Ignarro $L$, Pilla AA: Evidence-based use of pulsed electromagnetic field therapy in clinical plastic surgery. Aesthetic Surgery Journal 2009, 29(2):135-143.

52. Andrew C, Bassett L, Pawluk RJ, Pilla AA: Augmentation of Bone Repair by Inductively Coupled $\begin{array}{lllll}\text { Electromagnetic } \quad \text { Fields. } \quad \text { Science 1974, 184(4136):575-577 } & \text { \%U }\end{array}$ http://www.sciencemag.org/cgi/doi/510.1126/science.1184.4136.1575.

53. Bassett L, Tzitzikalakis G, Pawluk R, Bassett C: Prevention of disuse osteoporosis in the rat by means of pulsing electromagnetic fields. In: Electrical properties of bone and cartilage. Grune \& Stratton, New York; 1979: 311-332.

54. Cruess $R$, Kan K, Bassett $C$ : The effect of pulsing electromagnetic fields on bone metabolism in experimental disuse osteoporosis. Clinical Orthopaedics and Related Research ${ }^{\circledR}$ 1983, 173:245-250.

55. Funk RH, Monsees T, Özkucur N: Electromagnetic effects-From cell biology to medicine. Progress in histochemistry and cytochemistry 2009, 43(4):177-264.

56. Scott G, King JB: A prospective, double-blind trial of electrical capacitive coupling in the treatment of non-union of long bones. The Journal of Bone \& Joint Surgery 1994, 76(6):820-826 \%U https://insights.ovid.com/crossref?an=00004623-199406000-199400005.

57. Behari J, Arya V, Alex Z: Bone Fracture Healing using a Capacitatively Coupled Rffield. Journal of Bioelectricity 1991, 10(1-2):231-239.

58. Manjhi J, Mathur R, Behari J: Effect of low level capacitive-coupled pulsed electric field stimulation on mineral profile of weight-bearing bones in ovariectomized rats. Journal of Biomedical Materials Research Part B: Applied Biomaterials 2010, 92B(1):189-195 \%U http://doi.wiley.com/110.1002/jbm.b.31505.

59. Behari J, Behari J: Changes in bone histology due to capacitive electric field stimulation of ovariectomized rat. Indian Journal of Medical Research 2009, 130(6).

60. Behari J, Lochan R: Effects of low level pulsed radio frequency fields on induced osteoporosis in rat bone. 2003.

61. Skerry TM, Pead MJ, Lanyon LE: Modulation of bone loss during disuse by pulsed electromagnetic fields. Journal of Orthopaedic Research 1991, 9(4):600-608 \%U http://doi.wiley.com/610.1002/jor.1100090417.

62. McLeod KJ, Rubin CT: The effect of low-frequency electrical fields on osteogenesis. The Journal of Bone \& Joint Surgery 1992, 74(6):920-929 \%U http://Insights.ovid.com/crossref?an=00004623199274060-199200014.

63. Simske SJ, Wachtel $\mathrm{H}$, Luttges MW: Effect of localized pulsed electromagnetic fields on tailsuspension osteopenia in growing mice. Bioelectromagnetics 1991, 12(2):101-116 \%U http://doi.wiley.com/110.1002/bem.2250120205. 
64. Mishima S: The Effect of Long-Term Pulsing Electromagnetic Field Stimulation on Experimental Osteoporosis of Rats. Journal of UOEH 1988, 10(1):31-45 \%U https://www.jstage.jst.go.jp/article/juoeh/10/31/10 KJ00002505206/ article.

65. Takayama K, Nomura H, Tanaka J-i, Zborowski M, Harasaki H, Jacobs GB, Malchesky P, Licata AA, NosÉ $Y$ : Effect of a pulsing electromagnetic field on metabolically derived osteoporosis in rats: a pilot study. ASAIO transactions 1990, 36(3):M426-428.

66. Zati A, Gnudi S, Mongiorgi R, Giardino R, Fini M, Valdre G, Galliani I, Montagnani A: Effects of pulsed magnetic fields in the therapy of osteoporosis induced by ovariectomy in the rat. Bollettino della Societa italiana di biologia sperimentale 1993, 69(7-8):469-475.

67. Sert $C$, Denz M, Düz MZ, Akşen F, Kaya A: The preventive effect on bone loss of 50-Hz, 1-mT electromagnetic field in ovariectomized rats. Journal of Bone and Mineral Metabolism 2002, 20(6):345-349 \%U http://link.springer.com/310.1007/s007740200050.

68. Chang K, Chang WH-S: Pulsed electromagnetic fields prevent osteoporosis in an ovariectomized female rat model: A prostaglandin E2-associated process. Bioelectromagnetics 2003, 24(3):189-198 \%U http://doi.wiley.com/110.1002/bem.10078.

69. Tabrah FL, Ross P, Hoffmeier M, Gilbert Jr F: Clinical report on long-term bone density after shortterm EMF application. Bioelectromagnetics: Journal of the Bioelectromagnetics Society, The Society for Physical Regulation in Biology and Medicine, The European Bioelectromagnetics Association 1998, 19(2):75-78.

70. Garland DE, Adkins RH, Matsuno NN, Stewart CA: The Effect of Pulsed Electromagnetic Fields on Osteoporosis at the Knee in Individuals with Spinal Cord Injury. The Journal of Spinal Cord Medicine 1999, 22(4):239-245

http://www.tandfonline.com/doi/full/210.1080/10790268.10791999.11719576.

71. Ibiwoye MO, Powell KA, Grabiner MD, Patterson TE, Sakai Y, Zborowski M, Wolfman A, Midura RJ: Bone mass is preserved in a critical-sized osteotomy by low energy pulsed electromagnetic fields as quantitated by in vivo micro-computed tomography. Journal of Orthopaedic Research 2004, 22(5):1086-1093 \%U http://doi.wiley.com/1010.1016/j.orthres.2003.1012.1017.

72. Pilla AA: Low-intensity electromagnetic and mechanical modulation of bone growth and repair: are they equivalent? Journal of Orthopaedic Science 2002, 7(3):420-428 \% http://linkinghub.elsevier.com/retrieve/pii/S0949265815332097.

73. Fini M, Cadossi R, Canè V, Cavani F, Giavaresi G, Krajewski A, Martini L, Aldini NN, Ravaglioli A, Rimondini $L$ et al: The effect of pulsed electromagnetic fields on the osteointegration of hydroxyapatite implants in cancellous bone: a morphologic and microstructural in vivo study. Journal of Orthopaedic Research 2002, 20(4):756-763 \%U http://doi.wiley.com/710.1016/S07360266\%2801\%2900158-2900159.

74. Hart FX: Spreadsheet method for calculating the induced currents in bone-fracture healing by a low-frequency magnetic field. Bioelectromagnetics 1994, 15(5):465-482 \%U http://doi.wiley.com/410.1002/bem.2250150509.

75. Daish C, Blanchard R, Fox K, Pivonka P, Pirogova E: The Application of Pulsed Electromagnetic Fields (PEMFs) for Bone Fracture Repair: Past and Perspective Findings. Annals of biomedical engineering 2018, 46(4):525-542.

76. Massari L, Benazzo F, Falez F, Perugia D, Pietrogrande L, Setti S, Osti R, Vaienti E, Ruosi C, Cadossi R: Biophysical stimulation of bone and cartilage: state of the art and future perspectives. International orthopaedics 2019:1-13.

77. Markov MS: Pulsed electromagnetic field therapy history, state of the art and future. The Environmentalist 2007, 27(4):465-475. 
78. Panagopoulos DJ, Karabarbounis A, Margaritis LH: Mechanism for action of electromagnetic fields on cells. Biochemical and Biophysical Research Communications 2002, 298(1):95-102 \%U http://linkinghub.elsevier.com/retrieve/pii/S0006291X02023938.

79. Dimitriou R, Tsiridis E, Giannoudis PV: Current concepts of molecular aspects of bone healing. Injury 2005, 36(12):1392-1404.

80. Phillips A: Overview of the fracture healing cascade. Injury 2005, 36(3):S5-S7.

81. Tsiridis E, Upadhyay N, Giannoudis P: Molecular aspects of fracture healing: which are the important molecules? Injury 2007, 38(1):S11-S25.

82. Bodamyali T, Bhatt B, Hughes FJ, Winrow VR, Kanczler JM, Simon B, Abbott J, Blake DR, Stevens CR: Pulsed Electromagnetic Fields Simultaneously Induce Osteogenesis and Upregulate Transcription of Bone Morphogenetic Proteins 2 and 4 in Rat Osteoblastsin Vitro. Biochemical and Biophysical Research Communications 1998, 250(2):458-461 \%U http://linkinghub.elsevier.com/retrieve/pii/S0006291X98992439.

83. Guerkov HH, Lohmann CH, Liu Y, Dean DD, Simon BJ, Heckman JD, Schwartz Z, Boyan BD: Pulsed Electromagnetic Fields Increase Growth Factor Release by Nonunion Cells. Clinical Orthopaedics and Related Research 2001, 384:265-279 \%U https://insights.ovid.com/crossref?an=00003086200103000-200100031.

84. Lohmann CH, Schwartz Z, Liu Y, Guerkov H, Dean DD, Simon B, Boyan BD: Pulsed electromagnetic field stimulation of MG63 osteoblast-like cells affects differentiation and local factor production. Journal of Orthopaedic Research 2000, 18(4):637-646 \%U http://doi.wiley.com/610.1002/jor.1100180417.

85. Oreffo ROC, Bonewald L, Kukita A, Garrett IR, Seyedin SM, Rosen D, Mundy GR: Inhibitory Effects of the Bone-Derived Growth Factors Osteoinductive Factor and Transforming Growth Factor- $\beta$ on Isolated Osteoclasts*. Endocrinology 1990, 126(6):3069-3075 \%U https://academic.oup.com/endo/article-lookup/doi/3010.1210/endo-3126-3066-3069.

86. Schwartz Z, Simon BJ, Duran MA, Barabino G, Chaudhri R, Boyan BD: Pulsed electromagnetic fields enhance BMP-2 dependent osteoblastic differentiation of human mesenchymal stem cells. Journal of Orthopaedic Research 2008, 26(9):1250-1255 \%U http://doi.wiley.com/1210.1002/jor.20591.

87. Bannister SR, Lohmann CH, Liu Y, Sylvia VL, Cochran DL, Dean DD, Boyan BD, Schwartz Z: Shear force modulates osteoblast response to surface roughness. Journal of Biomedical Materials Research 2002, 60(1):167-174 \%U http://doi.wiley.com/110.1002/jbm.10037.

88. Schwartz Z, Fisher M, Lohmann CH, Simon BJ, Boyan BD: Osteoprotegerin (OPG) Production by Cells in the Osteoblast Lineage is Regulated by Pulsed Electromagnetic Fields in Cultures Grown on Calcium Phosphate Substrates. Annals of Biomedical Engineering 2009, 37(3):437-444 \%U http://link.springer.com/410.1007/s10439-10008-19628-10433.

89. Hofbauer LC, Gori F, Riggs BL, Lacey DL, Dunstan CR, Spelsberg TC, Khosla S: Stimulation of Osteoprotegerin Ligand and Inhibition of Osteoprotegerin Production by Glucocorticoids in Human Osteoblastic Lineage Cells: Potential Paracrine Mechanisms of Glucocorticoid-Induced Osteoporosis <sup>1</sup>. Endocrinology 1999, 140(10):4382-4389 \%U https://academic.oup.com/endo/article-lookup/doi/4310.1210/endo.4140.4310.7034.

90. Deckers MML, Karperien M, van der Bent C, Yamashita T, Papapoulos SE, Löwik CWGM: Expression of Vascular Endothelial Growth Factors and Their Receptors during Osteoblast Differentiation. Endocrinology 2000, 141(5):1667-1674 \%U https://academic.oup.com/endo/articlelookup/doi/1610.1210/endo.1141.1665.7458.

91. Deckers MML, van Bezooijen RL, van der Horst G, Hoogendam J, van der Bent C, Papapoulos SE, Löwik CWGM: Bone Morphogenetic Proteins Stimulate Angiogenesis through Osteoblast-Derived 
Vascular Endothelial Growth Factor A. Endocrinology 2002, 143(4):1545-1553 \%U https://academic.oup.com/endo/article-lookup/doi/1510.1210/endo.1143.1544.8719.

92. Villars $F$, Bordenave $L$, Bareille $R$, Amade J: Effect of human endothelial cells on Human Bone Marrow Stromal Cell phenotype: Role of VEGF? Journal of Cellular Biochemistry 2000, 79(4):672-685

93. Tepper OM, Callaghan MJ, Chang El, Galiano RD, Bhatt KA, Baharestani S, Gan J, Simon B, Hopper RA, Levine JP: Electromagnetic fields increase in vitro and in vivo angiogenesis through endothelial release of FGF-2. The FASEB journal 2004, 18(11):1231-1233.

94. Sun L-Y, Hsieh D-K, Yu T-C, Chiu H-T, Lu S-F, Luo G-H, Kuo TK, Lee OK, Chiou T-W: Effect of pulsed electromagnetic field on the proliferation and differentiation potential of human bone marrow mesenchymal stem cells. Bioelectromagnetics 2009, 30(4):251-260 \%U http://doi.wiley.com/210.1002/bem.20472.

95. Nicolin V, Ponti C, Baldini G, Gibellini D, Bortul R, Zweyer M, Martinelli B, Narducci P: In vitro exposure of human chondrocytes to pulsed electromagnetic fields. European Journal of Histochemistry 2009, 51(3):203-212.

96. Deng XL, Lau CP, Lai K, Cheung KF, Lau GK, Li GR: Cell cycle-dependent expression of potassium channels and cell proliferation in rat mesenchymal stem cells from bone marrow. Cell Proliferation 2007, 40(5):656-670 \%U http://doi.wiley.com/610.1111/j.1365-2184.2007.00458.x.

97. Kang Y, Perry RR: Effect of $\boldsymbol{\alpha}$-interferon on P-glycoprotein expression and function and on verapamil modulation of doxorubicin resistance. Cancer research 1994, 54(11):2952-2958.

98. Souviron Rodríguez $\mathrm{A}$, Ruiz Gómez $\mathrm{M}$, Morales Moreno J, Martínez Morillo M: Multidrug resistance in oncology. In: ANALES DE MEDICINA INTERNA-MADRID-ORGANO OFICIAL DE LA SOCIEDAD ESPANOLA DE MEDICINA INTERNA-: 1997. ARAN: 145-153.

99. Weaver JC: Electroporation of cells and tissues. IEEE Transactions on Plasma Science 2000, 28(1):2433 \%U http://ieeexplore.ieee.org/document/842820/.

100. Tsong TY: Electroporation of cell membranes. Biophysical Journal 1991, 60(2):297-306 \%U https://linkinghub.elsevier.com/retrieve/pii/S0006349591820549.

101. Mir LM, Orlowski S: Mechanisms of electrochemotherapy. Advanced Drug Delivery Reviews 1999, 35(1):107-118 \%U http://linkinghub.elsevier.com/retrieve/pii/S0169409X98000660.

102. Heller R, Gilbert R, Jaroszeski MJ: Clinical applications of electrochemotherapy. Advanced Drug Delivery Reviews 1999, 35(1):119-129 \%U http://linkinghub.elsevier.com/retrieve/pii/S0169409X98000672.

103. Hofmann GA, Dev SB, Dimmer S, Nanda GS: Electroporation therapy: a new approach for the treatment of head and neck cancer. IEEE Transactions on Biomedical Engineering 1999, 46(6):752-759 \%U http://ieeexplore.ieee.org/document/764952/.

104. Miklavčič D, Šemrov D, Mekid H, Mir LM: A validated model of in vivo electric field distribution in tissues for electrochemotherapy and for DNA electrotransfer for gene therapy. Biochimica et Biophysica Acta (BBA) - General Subjects 2000, 1523(1):73-83 \%U http://linkinghub.elsevier.com/retrieve/pii/S030441650000101X.

105. Liang Y, Hannan JC, Chang BK, Schoenlein PV: Enhanced potency of daunorubicin against multidrug resistant subline KB-ChR-8-5-11 by a pulsed magnetic field. Anticancer research 1997, 17(3C):20832088.

106. Harland JD, Liburdy RP: Environmental magnetic fields inhibit the antiproliferative action of tamoxifen and melatonin in a human breast cancer cell line. Bioelectromagnetics 1997, 18(8):555562 $\% U$ http://doi.wiley.com/510.1002/\%1028SICl\%291521- 
291186X\%281997\%292918\%291523A291528\%291523C291555\%291523A\%291523AAIDBEM291524\%291523E291523.291520.CO\%291523B291522-291521.

107. Murthy SN: Magnetophoresis: an approach to enhance transdermal drug diffusion. Die Pharmazie 1999, 54(5):377-379.

108. Morabito C, Guarnieri S, Fanò G, Mariggiò MA: Effects of acute and chronic low frequency electromagnetic field exposure on PC12 cells during neuronal differentiation. Cellular Physiology and Biochemistry 2010, 26(6):947-958.

109. Tuffet S, De Seze R, Moreau J-M, Veyret B: Effects of a strong pulsed magnetic field on the proliferation of tumour cells in vitro. Bioelectrochemistry and bioenergetics 1993, 30:151-160.

110. Loja T, Stehlikova O, Palko L, Vrba K, Rampl I, Klabusay M: Influence of pulsed electromagnetic and pulsed vector magnetic potential field on the growth of tumor cells. Electromagnetic biology and medicine 2014, 33(3):190-197.

111. Sadeghipour R, Ahmadian S, Bolouri B, Pazhang Y, Shafiezadeh M: Effects of extremely lowfrequency pulsed electromagnetic fields on morphological and biochemical properties of human breast carcinoma cells (T47D). Electromagnetic biology and medicine 2012, 31(4):425-435.

112. Crocetti S, Beyer C, Schade G, Egli M, Fröhlich J, Franco-Obregón A: Low intensity and frequency pulsed electromagnetic fields selectively impair breast cancer cell viability. PloS one 2013, 8(9):e72944.

113. Radeva M, Berg H: Differences in lethality between cancer cells and human lymphocytes caused by LF-electromagnetic fields. Bioelectromagnetics: Journal of the Bioelectromagnetics Society, The Society for Physical Regulation in Biology and Medicine, The European Bioelectromagnetics Association 2004, 25(7):503-507.

114. Koh EK, Ryu B-K, Jeong D-Y, Bang I-S, Nam MH, Chae K-S: A 60-Hz sinusoidal magnetic field induces apoptosis of prostate cancer cells through reactive oxygen species. International journal of radiation biology 2008, 84(11):945-955.

115. Tatarov I, Panda A, Petkov D, Kolappaswamy K, Thompson K, Kavirayani A, Lipsky MM, Elson E, Davis CC, Martin SS: Effect of magnetic fields on tumor growth and viability. Comparative medicine 2011, $61(4): 339-345$.

116. Emara S, EL-Kholy S, Kazem A, Hussein N, Al-dein RS: Therapeutic effects of low frequency pulsed electromagnetic fields on rat liver cancer. Res Inventy Int J Eng Sci 2013, 2:17-18.

117. Nuccitelli R, Pliquett U, Chen X, Ford W, James Swanson R, Beebe SJ, Kolb JF, Schoenbach KH: Nanosecond pulsed electric fields cause melanomas to self-destruct. Biochemical and Biophysical $\begin{array}{llll}\text { Research Communications } & \text { 343(2):351-360 }\end{array}$ https://linkinghub.elsevier.com/retrieve/pii/S0006291X06004256.

118. Berg H, GÜnther B, Hilger I, Radeva M, Traitcheva N, Wollweber L: Bioelectromagnetic field effects on cancer cells and mice tumors. Electromagnetic biology and medicine 2010, 29(4):132-143.

119. Costa F, de Oliveira A, Meirelles R, Zanesco T, Surjan R, Chammas M, Barbault A, Pasche B: A phase II study of amplitude-modulated electromagnetic fields in the treatment of advanced hepatocellular carcinoma (HCC). Journal of Clinical Oncology 2007, 25(18_suppl):15155-15155.

120. Barbault A, Costa FP, Bottger B, Munden RF, Bomholt F, Kuster N, Pasche B: Amplitude-modulated electromagnetic fields for the treatment of cancer: discovery of tumor-specific frequencies and assessment of a novel therapeutic approach. Journal of Experimental \& Clinical Cancer Research 2009, 28(1):51. 